\title{
The Role of Angioembolization In the Management of Blunt Renal Injuries: A Systematic Review
}

\section{Giovanni Liguori}

Azienda Sanitaria Universitaria Integrata di Trieste

Giacomo Rebez ( $\nabla$ giacomorebez@gmail.com )

Azienda Sanitaria Universitaria Integrata di Trieste https://orcid.org/0000-0001-7938-1579

\section{Andrea Salonia}

University Life-Health Saint Raphael: Universita Vita Salute San Raffaele

\section{Research article}

Keywords: Renal injury, Angioembolization, Trauma, Kidney

Posted Date: January 8th, 2021

DOI: https://doi.org/10.21203/rs.3.rs-141126/v1

License: @ (i) This work is licensed under a Creative Commons Attribution 4.0 International License. Read Full License

Version of Record: A version of this preprint was published at BMC Urology on August 6th, 2021. See the published version at https://doi.org/10.1186/s12894-021-00873-w. 


\section{Abstract \\ Background}

Non-operative management is established for low-grade (I-III) blunt renal injuries but it is getting increasingly popular even in high grade BRI thanks to angioembolization of active bleedings. To date a systematic review to assess the role of Angioembolization (RAE) in Blunt Renal Injuries (BRI) is not yet present in the literature.

\section{Methods}

a literature search was performed, 169 unilateral BRI were included; 124 high grade BRI (92 grade IV and 32 grade V renal injuries, respectively). Most common indication was hemodynamically stable patients with BRI grades II to IV and active contrast extravasation.

\section{Results}

Overall, the clinical success rate of RAE was $90 \%$ (range $73 \%-100 \%$ ). The rate of re-do embolization was $4.5 \%$ gaining a $100 \%$ success rate with a second attempt. Some authors reported successful RAE even in patients with grade V BRI, without major abdominal organ injuries and no pelvic fractures. RAE was performed also as adjunctive therapy prior to surgery. Most used agent was micro coils. Nephrectomy rate was $5.8 \%$, mortality rate was $3.2 \%$.

\section{Conclusions}

A multidisciplinary approach between interventional radiology and urology should be pursued to make every effort to perform endovascular therapy unless there are multiple visceral injuries or renal pedicle avulsion or expanding retroperitoneal hematoma necessitating surgery.

\section{Background}

Renal angioembolization (RAE) is an effective, minimally invasive treatment that was first developed in the 1970s (1). Renal injuries occur in approximately $10 \%$ of all abdominal trauma (2) and the kidney is the third most commonly injured solid organ. Every year, up to 245.000 renal injuries occur worldwide; blunt trauma is responsible for $80-90 \%$ of them (2) (3). Over the last few decades, non-operative management (NOM), including observation, transfusion, bed rest and/or renal angiogram with embolization (RAE), has become increasingly popular, especially for low-grade (I-III) blunt renal injuries (BRI). The published evidence is unclear about the role of NOM for higher grades (IV and V) (4) (5) (6). Over the last few decades, the management of patients with multiple injuries has improved thanks to specialized trauma units. In this context, NOM has become the treatment of choice for most renal injuries (7). Hemodynamic stability is one of the most important criteria to decide between operative and non-operative strategies in renal injuries (8). As a whole, primary conservative management is associated with a lower rate of nephrectomies, without increasing the immediate or the long-term morbidity. The improved staging of injury severity, thanks to advancing radiographic techniques, has enhanced the use of NOM (9). Furthermore, selective treatment with interventional radiology procedures has eventually reduced the need for surgical interventions in patients with both blunt and penetrating renal injuries (9) (10). Angioembolization has a central role in the management of hemodynamically stable patients with BRI (11) (12). Currently there are no validated criteria to identify patients who would benefit from embolization and its use remains controversial. This review is aimed to analyse the indications, techniques, efficacy, outcomes and complications rates of angioembolization in renal trauma.

\section{Methods}

PRISMA guidelines (13) were followed and a literature search was performed using MEDLINE, EMBASE, SCOPUS, Web of Science. Articles either published or e-published on angioembolization for BRI between January 2008 and September 2020 were searched. The Mesh terms used for search were: "renal" ("kidney"); "trauma" ("injury"); "embolization"; "angiography"; ("Renal Angio Embolization" or "RAE"). An additional manual search of EMBASE as well as bibliographies of each included study was done to identify studies not covered by the initial search.

\section{Study selection}

Page $2 / 10$ 
The results of the literature search were screened preliminarily by one reviewer (GR), then a secondary screening was performed by two other reviewers (GL, AS). The full texts and references of potentially appropriate literature were searched for further screening as recommended in the Preferred Reporting Items for Systematic Reviews and Meta-Analysis (PRISMA) guidelines.

\section{Inclusion criteria}

Retrospective studies evaluating adult patients who underwent RAE were included and the following data were required: 1) basic demographics of patients, medical history; 2) indications for RAE; 3) RAE techniques and/or embolic materials used; and, 4) the number of either severe life-threatening complications or complications which eventually needed further re-intervention or surgical management of the same kidney.

\section{Exclusion criteria}

The exclusion criteria were as follows: 1) reviews or editor letters and single case report; 2) non-English language publications; 3) studies only involving open injury, penetrating trauma, paediatric patients or iatrogenic injury; and, 4) studies with insufficient or unconfirmed information.

\section{Data extraction}

Data including the first author, publication year, number of patients, age, gender, indications and materials for embolization were extracted from the selected papers. The outcomes, number of successfully treated patients, severe and life-threatening complications (i.e., rebleeding, re-do RAE procedures, and contrast medium-induced renal failure) and the need for further surgical treatment were included. A meta-analytic approach was not possible due to the heterogeneity of the data and the lack of prospective studies.

\section{Final study selection}

Using these search criteria, an initial selection of 302 articles was considered. After title screening, we excluded case series, review articles and narrowed these downs to 81 studies. After a comprehensive review process of all retrieved titles and abstracts, 30 studies were preliminarily identified for full text evaluation. Of the 30 selected, 13 studies had been finally reviewed (Figure 1). A further sub-analysis of high-grade trauma cases was performed.

Indications for RAE: The indications were available in all studies. According to the American Association for the Surgery of Trauma (AAST) renal injury scale, the most common indication is blunt kidney trauma (II to IV grade) in hemodynamically stable patients. These patients usually present gross haematuria as the primary symptom of the renal injury. In the event that haematuria becomes persistent the patient could benefit from RAE (14) (15) (16).

CT criteria, such as perirenal hematoma rim distance (PRD), discontinuity of Gerota's fascia, or intravascular contrast extravasation (ICE) are used to select patients for RAE (12) (17) (18). Failure of conservative management due to unresponsive to fluid resuscitation hypotension represent further indication. Non operative management was described in hemodynamically unstable patients with grade $V$ renal injuries, both at the parenchymal and renovascular level (19) (6). It should be noted that those patients had no evidence of other intra-abdominal injuries requiring surgical exploration. All patients underwent RAE within 24 - 48 hours in urgency or emergency settings. Angioembolization of renal artery pseudoaneurysm and/or arteriovenous fistulas were not included in the selected studies.

Pre-procedure diagnostic work-up: Computed tomography scan and angiography are considered complementary to define the precise site of bleeding and the actual possibility to perform angioembolization. All patients were primarily screened with a CT scan to identify the bleeding site.

\section{Technique of RAE}

Route: Most RAE procedures were performed through femoral approach, using 4 - $6 \mathrm{~F}$ sized arterial sheaths (20). Radial or brachial approach was rare but necessary in case of iliac artery occlusion or unusual anatomic conditions (21).

Selective catheterization: Selective embolization was performed on angiographic findings, after comparing the CT and the arteriogram findings. Comparison between CT and arteriogram allows the choice between super selective embolization or embolization of the proximal branches of the renal artery (19) (17). 
Embolizingagents: Usually selection depends on preference of the interventional radiologists. Numerous general indications among different embolizing agents have been described (22); indeed, both temporary and permanent agents were used in the selected studies. The most used materials were micro coils and overall success rate was between $90 \%$ and $100 \%$, regardless of the material choice. (Table 2).

Technical success - The complete resolution of active extravasation was obtained between $90 \%$ and $100 \%$ of the cases. To achieve technical success, 4 patients required a more proximal vessel embolization to stop the angiographic extravasation (12) (14).

\section{Results}

Clinical success was achieved when further treatment was not required after embolization. Accordingly, the rate of clinical success ranges from $75-100 \%$ after the first attempt rising up to $100 \%$ after a second attempt (see Table 1). All 169 patients underwent unilateral RAE and seven required a re-do procedure. Re-embolization was effective in $7 / 7$ patients, gaining $100 \%$ success rate. Two patients underwent surgical exploration for other purposes after successful RAE and overall 11 patients required surgical intervention after the first RAE. Nine patients underwent surgical exploration after RAE failure: nephrectomy in 6/9 (66.7\%) and partial nephrectomy in 3/9 (33.3\%). Five of 169 patients deceased (2.9\%); of those, 1 died after surgery; 2 of post-traumatic brain injuries; 1 of post-pneumonia respiratory insufficiency and 1 of acute circulation failure despite a successful RAE. No one died of kidney injury related causes.

Table 1

Summary of clinical outcomes

\begin{tabular}{|c|c|c|c|c|c|c|c|c|c|c|}
\hline Year & Reference & $\begin{array}{l}\text { Number } \\
\text { of } \\
\text { patients }\end{array}$ & $\begin{array}{l}\text { AAST } \\
\text { II }\end{array}$ & $\begin{array}{l}\text { AAST } \\
\text { III }\end{array}$ & $\begin{array}{l}\text { AAST } \\
\text { IV }\end{array}$ & $\begin{array}{l}\text { AAST } \\
V\end{array}$ & $\begin{array}{l}\text { 1st } \\
\text { embolization } \\
\text { success rate }\end{array}$ & $\begin{array}{l}\text { 2nd } \\
\text { embolization } \\
\text { success rate }\end{array}$ & $\begin{array}{l}\text { Nephrectomies } \\
\text { after RAE } \\
\text { attempt }\end{array}$ & $\begin{array}{l}\text { Perioperative } \\
\text { mortality }\end{array}$ \\
\hline 2009 & Brewer & 9 & 0 & 0 & 0 & 9 & $100 \%$ & $\begin{array}{l}\text { not } \\
\text { performed }\end{array}$ & $\begin{array}{l}\text { RAE } \\
\text { successful }\end{array}$ & $12 \%$ \\
\hline 2010 & $\mathrm{Fu}$ & 14 & 0 & 2 & 11 & 1 & $85 \%$ & $100 \%$ & $\begin{array}{l}\text { RAE } \\
\text { successful }\end{array}$ & $0 \%$ \\
\hline 2010 & Menaker & 22 & 2 & 2 & 17 & 1 & $73 \%$ & $\begin{array}{l}\text { not } \\
\text { performed }\end{array}$ & $27 \%(6)$ & $0 \%$ \\
\hline 2010 & Stewart & 2 & 0 & 0 & 0 & 2 & $100 \%$ & $\begin{array}{l}\text { not } \\
\text { performed }\end{array}$ & $\begin{array}{l}\text { RAE } \\
\text { successful }\end{array}$ & $0 \%$ \\
\hline 2011 & Charbit & 10 & 0 & 1 & 4 & 5 & $90 \%$ & $\begin{array}{l}\text { not } \\
\text { performed }\end{array}$ & $10 \%(1)$ & $0 \%$ \\
\hline 2012 & $\begin{array}{l}\text { Van Der } \\
\text { Vlies }\end{array}$ & 6 & 0 & 1 & 2 & 3 & $100 \%$ & $\begin{array}{l}\text { not } \\
\text { performed }\end{array}$ & $16 \%(1)^{\star}$ & $0 \%$ \\
\hline 2013 & $\begin{array}{l}\text { Van de } \\
\text { Wilden }\end{array}$ & 25 & 0 & 0 & 20 & 5 & $92 \%$ & $100 \%$ & $\begin{array}{l}\text { RAE } \\
\text { successful }\end{array}$ & $0 \%$ \\
\hline 2014 & Saour & 10 & 0 & 1 & 4 & 5 & $90 \%$ & $\begin{array}{l}\text { not } \\
\text { performed }\end{array}$ & $10 \%(1)$ & $0 \%$ \\
\hline 2014 & Rao & 16 & 0 & 12 & 3 & 1 & $93 \%$ & $\begin{array}{l}\text { not } \\
\text { performed }\end{array}$ & $7 \%(1)$ & $6 \%$ \\
\hline 2015 & Vozianov & 20 & 2 & 11 & 7 & 0 & $90 \%$ & $100 \%$ & $\begin{array}{l}\text { RAE } \\
\text { successful }\end{array}$ & $0 \%$ \\
\hline 2018 & Yanagi & 17 & 0 & 0 & 17 & 0 & $100 \%$ & $\begin{array}{l}\text { not } \\
\text { performed }\end{array}$ & $\begin{array}{l}\text { RAE } \\
\text { successful }\end{array}$ & $17 \%$ \\
\hline 2019 & Pretorius & 7 & 0 & 3 & 4 & 0 & $85 \%$ & $100 \%$ & $\begin{array}{l}\text { RAE } \\
\text { successful }\end{array}$ & $0 \%$ \\
\hline 2020 & Chen & 9 & 4 & 0 & 3 & 0 & $100 \%$ & $\begin{array}{l}\text { not } \\
\text { performed }\end{array}$ & $\begin{array}{l}\text { RAE } \\
\text { successful }\end{array}$ & $12 \%$ \\
\hline
\end{tabular}

\section{Focus on high-grade injury}

124 patients with high grade renal injuries were included; 92 with grade IV (73\%); and 32 with grade V (27\%). Overall clinical success was reached in 115 patients (92\%), whereas $9(8 \%)$ underwent surgical exploration (1 partial nephrectomy and 6 nephrectomies were 
performed). Moreover, Stewart (6) reported 10 grade $V$ hemodynamically unstable patients treated with RAE with technical and clinical success. Similarly, Van der Vlies (23) reported 1 hemodynamically unstable patient successfully treated with RAE and two patients who, before undergoing emergency laparotomy, underwent RAE in addition. Hemodynamically unstable patients who successfully underwent RAE were very selected patients without major abdominal injuries nor pelvic fracture. No patient deceased within the hemodynamically unstable cohort after RAE attempt.

Charbit (17) and Fu (18) reported two retroperitoneal abscesses successfully drained and only 1 patient presented a perinephric urinoma. No patient required dialytic treatment after discharge. Post-embolization syndrome, comprising fever, leucocytosis, and pain, was a common and temporary complication often related to the trauma itself, especially in high grade injuries. Consequently, it was not considered as a complication among the study outcomes. Pneumoniae, deep vein thrombosis and complications related to the prolonged bed rest could not be included due to the design of the studies. Indeed, studies design makes it impossible to differentiate from NOM with RAE vs NOM without RAE vs operative management vs failure of NOM in the follow up.

The risk of bias was minimized by the different revision of papers made by 3 authors (GR, GL, AS).

Recommendations and clinical practice are based on observational or retrospective studies, as well as clinical principles and expert opinions. Urgency setting makes it difficult to blind participants or study personnel to an intervention group. A non-blinded prospective study could be technically possible but to date there are none on this subject.

Most of the choices were based on the clinical judgment of the trauma-surgeon and radiologist (interventionist) present without a shared protocol. These decisions could not always be retrieved from the trauma registry or electronic medical record.

Several limitations are present in this review; first of all, the lack of prospective randomized clinical trials and secondly the low number of available studies about this topic and their heterogeneity. Moreover, retrieved data did not allow us to perform a comprehensive comparative evaluation of RAE vs. observation vs. surgery. Even in highly experienced trauma centres the number of angioembolization performed on renal trauma in a year is very low (max 10 procedures in a year). Long-term multi-institutional collaborative research with larger cohorts are needed to confirm outcomes and to produce solid indications for the urgency/emergency setting of RAE.

\section{Discussion}

Despite the absence of strict recommendations, non-operative management seems to be the best choice in most patients with BRI (24). Our review underlines how RAE is becoming a first-line therapy to stop active bleeding in stable kidney trauma. Early RAE seems to be effective on hemodynamically stable patients without concomitant organ injuries, visceral injuries or pelvic fractures, from grade II up to grade IV renal trauma. Angioembolization seems to be effective where a truly conservative therapy could fail (III and IV grades); providing a minimally invasive treatment instead of surgery. A second chance, after first attempt failure, can be worthwhile if clinical parameters remain stable. Indeed, the second attempt seems to raise the success rate avoiding unnecessary nephrectomies in few selected patients.

Our findings are consistent with latest guidelines since hemodynamic stability is the main criterion for non-operative management of kidney trauma. An important difference between guidelines regard hemodynamically stable with high-grade trauma. The SIU guidelines recommend exploratory laparotomy, the EAU guidelines recommend renal exploration only if the injury is vascular, and the AUA guidelines recommend initial conservative management (25) (26) (27). Angioembolization has a key role in the non-operative management but currently there are no validated criteria to identify patients who require RAE (28). Anyway, a not recent consensus statement recommends operative management for life-threatening haemorrhage, renal pedicle avulsion and for an expanding retroperitoneal hematoma that is not contained (29).

Surely some of the lower grade injuries included in the review could probably have been managed in a truly conservative way without RAE. This surely may increase the overall clinical success rate. As a whole, grade I-II BRI are the most frequent types of blunt trauma and can benefit from a truly conservative approach without angiography. These patients should not be treated routinely with RAE, owing to the risk of inducing unnecessary renal infarctions and overtreatment (30).

Although RAE was reported successful in a very small cohort of hemodynamically unstable high-grade renal injuries the data is still not robust enough to support this treatment as a choice. Grade IV and V injuries are uncommon and therefore most of these studies lack an appropriate sample size to create statistical significance and produce valid recommendations. Indeed, RAE may prevent nephrectomy of grade $V$ injuries; however, many of these cases should need to repeat embolization (22) and moreover angioembolization failure in patients with grade IV and $\mathrm{V} B \mathrm{BI}$ is not rare (31).

Page 5/10 
Furthermore, embolization may be considered as an adjunctive therapy prior to surgery, if easily accessible and not time consuming.

The risk of bias was minimized by the different revision of papers made by 3 authors (GR, GL, AS).

Some limitations are present as recommendations and clinical practice are based on observational or retrospective studies, as well as clinical principles and expert opinions. Urgency setting makes it difficult to blind participants or study personnel to an intervention group. A non-blinded prospective study could be technically possible but to date there are none on this subject. Most of the choices were based on the clinical judgment of the trauma-surgeon and radiologist (interventionist) present without a shared protocol. These decisions could not always be retrieved from the trauma registry or electronic medical record. The lack of prospective randomized clinical trials and secondly the low number of available studies about this topic and their heterogeneity are a limit of this study. Moreover, retrieved data did not allow us to perform a comprehensive comparative evaluation of RAE vs. observation vs. surgery. Even in highly experienced trauma centres the number of angioembolization performed on renal trauma in a year is very low (max 10 procedures in a year). Long-term multiinstitutional collaborative research with larger cohorts are needed to confirm outcomes and to produce solid indications for the urgency/emergency setting of RAE.

\section{Conclusion}

A multidisciplinary approach between interventional radiology and urology should be pursued to make the best effort to perform endovascular therapy. Angioembolization seems to be effective unless there are multiple visceral injuries necessitating surgery and/or hemodynamic instability. Very accurate preprocedural planning and careful post procedural monitoring should be performed to optimize clinical outcomes; a second try of RAE can be worthwhile. Multi-institutional collaborative research can improve the quality of evidence to produce more solid indications on angioembolization in the management of urological trauma.

\section{Key Points}

- Angioembolization seems to be effective where a truly conservative therapy could fail (III and IV grades);

- A second attempt can be worthwhile;

- High-grade trauma with hemodynamic instability: data is not robust enough to support angioembolization as a choice;

- More solid indications on renal trauma angioembolization are required.

\section{Abbreviations}

RAE

Renal angioembolization

NOM

Non operative management

BRI

Blunt renal injuries

\section{Declarations}

Ethics approval and consent to participate: not applicable.

Consent for Publication: not applicable. We state that this paper has not been previously published and is not under consideration by another journal.

Availability of data and material: We declare that all material and all data are available and does not involve plagiarism.

Competing interests: No conflict of interest to declare.

Funding: no funding to declare. Authors have no direct or indirect commercial financial incentive associated with publishing the manuscript.

Authors' contributions: All authors have contributed to the information and material submitted for publication and all authors have read and approved the manuscript.

Design of the work: GL; Acquisition, analysis, interpretation of data: GR,GL,AS; Drafted the work and substantively revised it: AS. 
All Authors have approved the submitted version (and any substantially modified version that involves the author's contribution to the study); All authors have agreed both to be personally accountable for the author's own contributions and to ensure that questions related to the accuracy or integrity of any part of the work, even ones in which the author was not personally involved, are appropriately investigated, resolved, and the resolution documented in the literature.

\section{Acknowledgements: not applicable.}

\section{References}

1. ALMGÅRD LE, FERNSTRÖM I, HAVERLING M, LJUNGQVIST A. Treatment of Renal Adenocarcinoma by Embolic Occlusion of the Renal Circulation. British Journal of Urology. 1973;

2. Wessells H, Suh D, Porter JR, Rivara F, MacKenzie EJ, Jurkovich GJ, et al. Renal injury and operative management in the United States: Results of a population-based study. Journal of Trauma. 2003;

3. Morey AF, Brandes S, Dugi DD, Armstrong JH, Breyer BN, Broghammer JA, et al. Urotrauma: AUA guideline. Journal of Urology. 2014;

4. Santucci RA, Fisher MB. The literature increasingly supports expectant (conservative) management of renal trauma - A systematic review. Journal of Trauma - Injury, Infection and Critical Care. 2005.

5. Altman AL, Haas C, Dinchman KH, Spirnak JP. Selective nonoperative management of blunt grade 5 renal injury. Journal of Urology. 2000;

6. Stewart AF, Brewer ME, Daley BJ, Klein FA, Kim ED. Intermediate-term follow-up of patients treated with percutaneous embolization for grade 5 blunt renal trauma. Journal of Trauma - Injury, Infection and Critical Care. 2010;

7. Santucci RA, McAninch JW, Safir M, Mario LA, Service S, Segal MR. Validation of the American Association for the Surgery of Trauma organ injury severity scale for the kidney. In: Journal of Trauma - Injury, Infection and Critical Care. 2001.

8. Rogers CG, Knight V, MacUra KJ, Ziegfeld S, Paidas CN, Mathews RI. High-grade renal injuries in children - Is conservative management possible? Urology. 2004;

9. J. M, M.F. B, P. D, J. K, P.L. R, N.M. C. Predictors of outcome for blunt high grade renal injury treated with conservative intent. Journal of Urology. 2011;

10. Chow SJD, Thompson KJ, Hartman JF, Wright ML. A 10-year review of blunt renal artery injuries at an urban level I trauma centre. Injury. 2009;

11. Lanchon C, Fiard G, Arnoux V, Descotes JL, Rambeaud JJ, Terrier N, et al. High Grade Blunt Renal Trauma: Predictors of Surgery and Long-Term Outcomes of Conservative Management. A Prospective Single Center Study. Journal of Urology. 2016;

12. van der Wilden GM, Velmahos GC, Joseph DK, Jacobs L, DeBusk MG, Adams CA, et al. Successful Nonoperative management of the most severe blunt renal injuries: A multicenter study of the research consortium of new england centers for trauma. JAMA Surgery. 2013;

13. Stewart LA, Clarke M, Rovers M, Riley RD, Simmonds M, Stewart G, et al. Preferred reporting items for a systematic review and metaanalysis of individual participant data: The PRISMA-IPD statement. JAMA - Journal of the American Medical Association. 2015.

14. Vozianov S, Sabadash M, Shulyak A. Experience of renal artery embolization in patients with blunt kidney trauma. Central European Journal of Urology. 2015;

15. Yanagi M, Suzuki Y, Hamasaki T, Mizunuma K, Arai M, Yokota H, et al. Early Transcatheter Arterial Embolization for the American Association for the Surgery of Trauma Grade 4 Blunt Renal Trauma in Two Institutions. Journal of Nippon Medical School. 2018;

16. Breyer BN, McAninch JW, Elliott SP, Master VA. Minimally Invasive Endovascular Techniques to Treat Acute Renal Hemorrhage. Journal of Urology. 2008;

17. Charbit J, Manzanera J, Millet I, Roustan JP, Chardon P, Taourel P, et al. What are the specific computed tomography scan criteria that can predict or exclude the need for renal angioembolization after high-grade renal trauma in a conservative management strategy? Journal of Trauma - Injury, Infection and Critical Care. 2011;

18. Fu CY, Wu SC, Chen RJ, Chen YF, Wang YC, Chung PK, et al. Evaluation of need for angioembolization in blunt renal injury: discontinuity of Gerota's fascia has an increased probability of requiring angioembolization. American Journal of Surgery. 2010;

19. Brewer ME, Strnad BT, Daley BJ, Currier RP, Klein FA, Mobley JD, et al. Percutaneous Embolization for the Management of Grade 5 Renal Trauma in Hemodynamically Unstable Patients: Initial Experience. Journal of Urology. 2009;

20. Muller A, Rouvière O. Renal artery embolization-indications, technical approaches and outcomes. Nature Reviews Nephrology. 2015. 21. Sauk S, Zuckerman DA. Renal artery embolization. Seminars in Interventional Radiology. 2011.

Page $7 / 10$ 
22. Hotaling JM, Sorensen MD, Smith TG, Rivara FP, Wessells H, Voelzke BB. Analysis of diagnostic angiography and angioembolization in the acute management of renal trauma using a national data set. Journal of Urology. 2011;

23. van der Vlies $\mathrm{CH}$, Olthof DC, van Delden OM, Ponsen KJ, de La Rosette JJMCH, de Reijke TM, et al. Management of blunt renal injury in a level 1 trauma centre in view of the European guidelines. Injury. 2012;

24. Mingoli A, Torre M la, Migliori E, Cirillo B, Zambon M, Sapienza P, et al. Operative and nonoperative management for renal trauma: Comparison of outcomes. A systematic review and meta-analysis. Therapeutics and Clinical Risk Management. 2017.

25. Bryk DJ, Zhao LC. Guideline of guidelines: A review of urological trauma guidelines. BJU International. 2016.

26. Robert M, Drianno N, Muir G, Delbos O, Guiter J. Management of major blunt renal lacerations: Surgical or nonoperative approach? European Urology. 1996;

27. Keihani S, Xu Y, Presson AP, Hotaling JM, Nirula R, Piotrowski J, et al. Contemporary management of high-grade renal trauma. Journal of Trauma and Acute Care Surgery. 2018;

28. Coccolini F, Moore EE, Kluger Y, Biffl W, Leppaniemi A, Matsumura Y, et al. Kidney and uro-trauma: WSES-AAST guidelines. World Journal of Emergency Surgery. 2019.

29. Santucci RA, Wessells H, Bartsch G, Descotes J, Heyns CF, McAninch JW, et al. Evaluation and management of renal injuries: Consensus statement of the renal trauma subcommittee. In: BJU International. 2004.

30. Glass AS, Appa AA, Kenfield SA, Bagga HS, Blaschko SD, McGeady JB, et al. Selective angioembolization for traumatic renal injuries: A survey on clinician practice. World Journal of Urology. 2014;

31. Sugihara T, Yasunaga H, Horiguchi H, Nishimatsu H, Fukuhara H, Enomoto $Y$, et al. Management trends, angioembolization performance and multiorgan injury indicators of renal trauma from Japanese administrative claims database. International Journal of Urology. 2012;

32. Menaker J, Joseph B, Stein DM, Scalea TM. Angiointervention: High rates of failure following blunt renal injuries. World Journal of Surgery. 2011;

33. Saour M, Charbit J, Millet I, Monnin V, Taourel P, Klouche K, et al. Effect of renal angioembolization on post-traumatic acute kidney injury after high-grade renal trauma: A comparative study of 52 consecutive cases. Injury. 2014;

34. Pretorius R, Vlok S, van der Merwe A, Zarrabi AD, du Toit K. Renal artery embolisation: Indications and utilisation at Tygerberg Hospital. South African Journal of Surgery. 2019;

35. Chen J, Cai W, Li L. Profi le of renal artery embolization (RAE) for renal trauma: A comparison of data from two major trauma center. International Braz J Urol. 2020;

\section{Tables}

\section{Table 1: Summary of clinical outcomes}




\begin{tabular}{|c|c|c|c|c|c|c|c|c|c|c|}
\hline Year & Reference & $\begin{array}{l}\text { Number } \\
\text { of } \\
\text { patients }\end{array}$ & $\begin{array}{l}\text { AAST } \\
\text { II }\end{array}$ & $\begin{array}{l}\text { AAST } \\
\text { III }\end{array}$ & $\begin{array}{l}\text { AAST } \\
\text { IV }\end{array}$ & $\begin{array}{l}\text { AAST } \\
V\end{array}$ & $\begin{array}{l}1^{\text {st }} \\
\text { embolization } \\
\text { success rate }\end{array}$ & $\begin{array}{l}2^{\text {nd }} \\
\text { embolization } \\
\text { success rate }\end{array}$ & $\begin{array}{l}\text { Nephrectomies } \\
\text { after RAE } \\
\text { attempt }\end{array}$ & $\begin{array}{l}\text { Perioperative } \\
\text { mortality }\end{array}$ \\
\hline 2009 & Brewer & 9 & 0 & 0 & 0 & 9 & $100 \%$ & $\begin{array}{l}\text { not } \\
\text { performed }\end{array}$ & $\begin{array}{l}\text { RAE } \\
\text { successful }\end{array}$ & $12 \%$ \\
\hline 2010 & $\mathrm{Fu}$ & 14 & 0 & 2 & 11 & 1 & $85 \%$ & $100 \%$ & $\begin{array}{l}\text { RAE } \\
\text { successful }\end{array}$ & $0 \%$ \\
\hline 2010 & Menaker & 22 & 2 & 2 & 17 & 1 & $73 \%$ & $\begin{array}{l}\text { not } \\
\text { performed }\end{array}$ & $27 \%(6)$ & $0 \%$ \\
\hline 2010 & Stewart & 2 & 0 & 0 & 0 & 2 & $100 \%$ & $\begin{array}{l}\text { not } \\
\text { performed }\end{array}$ & $\begin{array}{l}\text { RAE } \\
\text { successful }\end{array}$ & $0 \%$ \\
\hline 2011 & Charbit & 10 & 0 & 1 & 4 & 5 & $90 \%$ & $\begin{array}{l}\text { not } \\
\text { performed }\end{array}$ & $10 \%(1)$ & $0 \%$ \\
\hline 2012 & $\begin{array}{l}\text { Van Der } \\
\text { Vlies }\end{array}$ & 6 & 0 & 1 & 2 & 3 & $100 \%$ & $\begin{array}{l}\text { not } \\
\text { performed }\end{array}$ & $16 \%(1)^{\star}$ & $0 \%$ \\
\hline 2013 & $\begin{array}{l}\text { Van de } \\
\text { Wilden }\end{array}$ & 25 & 0 & 0 & 20 & 5 & $92 \%$ & $100 \%$ & $\begin{array}{l}\text { RAE } \\
\text { successful }\end{array}$ & $0 \%$ \\
\hline 2014 & Saour & 10 & 0 & 1 & 4 & 5 & $90 \%$ & $\begin{array}{l}\text { not } \\
\text { performed }\end{array}$ & $10 \%(1)$ & $0 \%$ \\
\hline 2014 & Rao & 16 & 0 & 12 & 3 & 1 & $93 \%$ & $\begin{array}{l}\text { not } \\
\text { performed }\end{array}$ & $7 \%(1)$ & $6 \%$ \\
\hline 2015 & Vozianov & 20 & 2 & 11 & 7 & 0 & $90 \%$ & $100 \%$ & $\begin{array}{l}\text { RAE } \\
\text { successful }\end{array}$ & $0 \%$ \\
\hline 2018 & Yanagi & 17 & 0 & 0 & 17 & 0 & $100 \%$ & $\begin{array}{l}\text { not } \\
\text { performed }\end{array}$ & $\begin{array}{l}\text { RAE } \\
\text { successful }\end{array}$ & $17 \%$ \\
\hline 2019 & Pretorius & 7 & 0 & 3 & 4 & 0 & $85 \%$ & $100 \%$ & $\begin{array}{l}\text { RAE } \\
\text { successful }\end{array}$ & $0 \%$ \\
\hline 2020 & Chen & 9 & 4 & 0 & 3 & 0 & $100 \%$ & $\begin{array}{l}\text { not } \\
\text { performed }\end{array}$ & $\begin{array}{l}\text { RAE } \\
\text { successful }\end{array}$ & $12 \%$ \\
\hline
\end{tabular}

Legend table 1: All the included studies were retrospective. No patient who had previously attempted a second RAE underwent surgical exploration and nephrectomy. Only 3 partial nephrectomy were performed all by Menaker. No renorrhaphy was performed in any patient. Perioperative mortality refers to overall mortality not only related to renal trauma but also to other abdominal/ skeletal injuries.

*1 hemodynamically unstable patient underwent RAE planned before undergoing surgery to stabilize the bleeding.

Table 2: Embolizing materials

\begin{tabular}{|c|c|c|c|c|c|c|c|c|}
\hline Year & Author & $\begin{array}{l}\text { Number of } \\
\text { patients }\end{array}$ & Gelfoam & Pva & Microcoils & NBCA & $\begin{array}{l}\text { Microcoils + } \\
\text { Gelfoam }\end{array}$ & $\begin{array}{l}\text { Success } \\
\%\end{array}$ \\
\hline 2009 & Brewer et all & 9 & $4 / 944 \%$ & 0 & (5/9) 66\% & 0 & 0 & $100 \%$ \\
\hline 2010 & Stewart et all & 10 & 0 & 0 & $\begin{array}{l}(10 / 10) \\
100 \%\end{array}$ & 0 & 0 & $100 \%$ \\
\hline 2011 & Charbit et all & 10 & (4 ) $40 \%$ & 0 & $(6 / 10) 60 \%$ & 0 & 0 & $90 \%$ \\
\hline 2015 & $\begin{array}{l}\text { Vozianov et } \\
\text { all }\end{array}$ & 20 & (6) $30 \%$ & $\begin{array}{l}(14) \\
70 \%\end{array}$ & 0 & 0 & 0 & $90 \%$ \\
\hline 2018 & Yanagi et all & 17 & (8) $47 \%$ & 0 & (2) $11 \%$ & $\begin{array}{l}(1) \\
5 \%\end{array}$ & (6) $35 \%$ & $100 \%$ \\
\hline
\end{tabular}

Legend: Embolizing materials were selected according to radiologists preference 


\section{Figures}

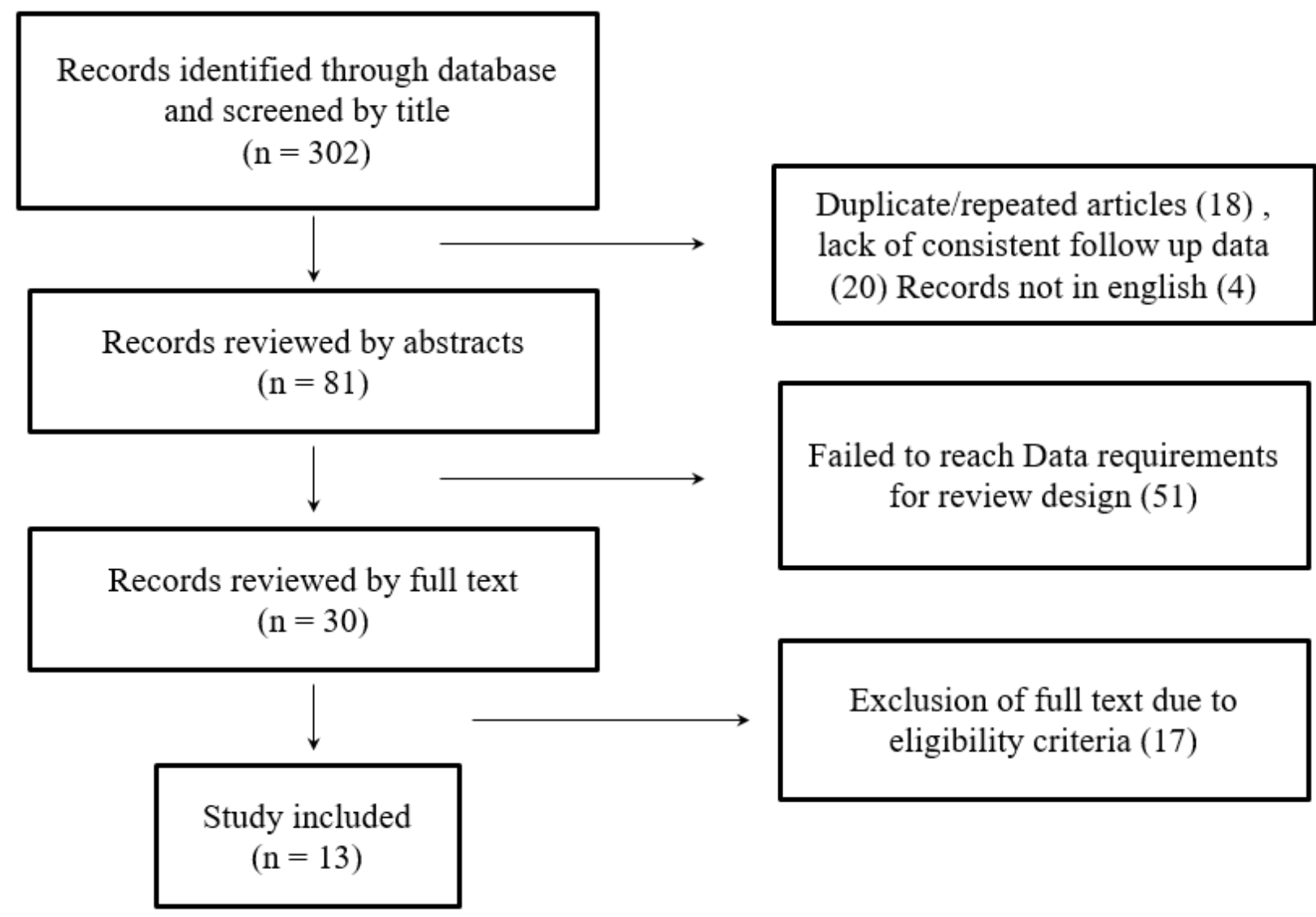

Figure 1

Flow Chart

\section{Supplementary Files}

This is a list of supplementary files associated with this preprint. Click to download.

- PRISMAPchecklistcopy.pdf 